\title{
Dairy cow behavior affects the availability of an automatic milking system
}

\author{
J. A. Jacobs, ${ }^{* 1}$ K. Ananyeva, $†$ and J. M. Siegford ${ }^{\star 2}$ \\ *Department of Animal Science, and \\ †Department of Crop and Soil Sciences, Michigan State University, East Lansing 48824
}

\section{ABSTRACT}

Facility design can affect the accessibility of an automatic milking system (AMS). In particular, gates and alleys positioned around the AMS may affect cow traffic and cow behavior, potentially affecting the duration of time the AMS is available for milking. Eighty-four Holstein cows of various parities and days in milk were randomly divided between 2 groups, each group having access to its own AMS. Cow locations and behaviors in the AMS entrance and exit areas, as well as in the adjacent holding area, were recorded continuously for 14 d. Cows receiving a "no-milking" decision (i.e., cow is rejected from the milking stall due to a recent milking event) took longer to exit the milking stall $(18.2 \pm 1.33$ $\mathrm{s})$, and were more likely to circle and re-enter the AMS $(0.8 \pm 0.15)$ compared with cows receiving a milking decision $(16.2 \pm 1.09 \mathrm{~s} ; 0.2 \pm 0.03)$. Cows exiting the AMS hesitated for long periods when another cow was near the exit gate $(192.93 \pm 1.11 \mathrm{~s})$ or in the general holding area $(101.04 \pm 1.07 \mathrm{~s})$. Cows in late lactation had a greater probability of hesitating in the exit alley for long periods $(0.55 \pm 0.09)$ compared with cows in early lactation $(0.15 \pm 0.07)$, regardless of whether cows were in the holding area. Primiparous cows were more likely to block other cows trying to exit $(0.60 \pm$ $0.13)$ compared with multiparous cows $(0.29 \pm 0.09)$. Occasionally, blocking events led to "back-up" events, in which the AMS became unavailable for new cow access due to a back up of cows through the exit alley into the milking stall. The AMS was empty (not occupied) for 10 and $18 \%$ (groups 1 and 2, respectively) of the day; therefore, it was possible that back-up events would simply reduce the amount of time the AMS was empty. The duration of back-up events and AMS empty events had a negative relationship in group $1(\mathrm{r}=-0.74)$, but no such relationship was observed in group 2 . The differences in time budgets between the 2 groups suggest

\footnotetext{
Received July 20, 2011.

Accepted November 29, 2011.

${ }^{1}$ Current address: Department of Population Medicine, Ontario Veterinary College, University of Guelph, Guelph, Ontario, N1G 2W1, Canada.

${ }^{2}$ Corresponding author: siegford@msu.edu
}

that the effect of back-up events on AMS availability may be dependent on group social dynamics.

Key words: robotic milking, cow traffic, behavior

\section{INTRODUCTION}

An automatic milking system (AMS) relies on a cow voluntarily entering and exiting the milking stall without assistance from farm personnel and as an individual apart from its herd. As a result, understanding the interactions between cows and their environment that influence movement through the AMS becomes imperative to the success of the system. To ensure a high percentage of individual voluntary milking visits, cows must be motivated to enter the milking stall of their own accord. The motivation for cows being milked is weak and highly variable between cows, relative to the strong, consistent motivation that cows have for eating (Prescott et al., 1998). For this reason, a palatable feed concentrate is usually offered in the AMS milking stall. Additionally, several researchers have identified the importance of a large holding area near the milking stall to reduce social competition for access to the AMS (Hermans et al., 2003; Melin et al., 2006; Rodenburg, 2007). The holding area, which is an open area in front of the milking stall, is designed to provide an area for cows to wait for access to the AMS. A minimum of $6.09 \mathrm{~m}$ of space between the freestall area and the milking stall (i.e., the holding area) is recommended to encourage efficient traffic flow from stalls into the AMS (Rodenburg, 2007).

Most AMS incorporate entrance and exit alleys and gates to encourage an efficient queue before and after milking, potentially reducing negative social interactions that might influence AMS visit frequency. Anecdotally, 1-way exit alleys leading away from the milking stall have been recommended to facilitate exit traffic and decrease aggressive interactions. Little research has investigated potential behavioral implications of these holding area and alley design recommendations. Stefanowska and colleagues (1999) reported a decrease in the rate of movement of cows in the exit alley when other cows were present in the holding area. Additionally in this situation, the exiting cow and the cow(s) 
in the holding area engaged in aggressive interactions more than $50 \%$ of the time.

When the new barn at the Kellogg Biological Station (KBS) Pasture Dairy Research Education Center at Michigan State University was designed, a 7.32-m holding area and 2.45-m-long entrance and exit alleys were incorporated to help facilitate cow traffic in and around the AMS, following the recommendations described above. Despite the inclusion of these features, cows were frequently observed hesitating in the exit alley. Furthermore, cows in the holding area were regularly observed blocking cows attempting to leave the exit alley by positioning themselves at the end of the alley near the 1-way exit gates. Occasionally, these blocking events would lead to a "back-up" of cows in the exit alley, and recently milked cows would be unable to completely exit the milking stall. As a direct consequence of this back-up, the AMS was not able to accept a new cow for milking. Thus, despite following recommendations, anecdotal observation suggested several cow-traffic problems that could affect the efficiency of the system and the individual time budgets of cows. These problems may cause a decrease in the availability of the system that could equate to fewer milking events each day. In addition, negative social interactions at the AMS may reduce the motivation of cows being blocked to revisit the milking stall of their own accord.

The objective was to investigate interactions between cows with respect to their environment and determine potential implications on the availability of an AMS at the KBS dairy farm. Descriptions of factors relating to hesitation in the exit alley, the effect of unsuccessful milking visits (i.e., a cow enters the milking stall and is rejected because she has been recently milked) on the efficiency of the system, and the characterization of cows that hesitate and cows that block others were made to provide insight into the potential problems associated with facility designs. Additionally, the relationship between blocking and successful milking events was investigated to further evaluate the effect that facility design and cow behavior have on the efficiency of the AMS. The hypotheses were (1) that unsuccessful milking events would lead to decreased AMS exit duration and result in more frequent circling compared with successful milking events; (2) that the duration of hesitation in the exit alley would increase with the presence of cows in the holding area or near 1-way exit alley gates; (3) that hesitating cows would share similar characteristics (e.g., would be primiparous, in late lactation with no horns), and blocking cows would share similar characteristics (e.g., would be multiparous, in early lactation with horns); and (4) last, that back-up events would negatively affect the availability of the AMS by reducing the percentage of time spent on successful milking events.

\section{MATERIALS AND METHODS}

Prior to the start of the study, all protocols were submitted to and approved by the Michigan State University Institutional Animal Care and Use Committee.

\section{Animals and Husbandry}

Eighty-four lactating Holstein dairy cows were used to analyze the efficiency of the KBS dairy AMS facility design by assessing cow behavior in and around the AMS. Cows were divided into 2 groups ( $\mathrm{n}=42$ /group) balanced for parity and stage of lactation, with each group having access to a single AMS (Table 1). Cows were chosen based on the expectation that they would be lactating for the full duration of the project. Cows were in their first to seventh lactation with an average of $194 \pm 13.9$ DIM.

The AMS entrance and exit gate designs for cow traffic flow were mirror images between the groups because the "handedness" of the milking system was different for both groups. Group 1 had access to a left-handed AMS, whereas group 2 had access to a right-handed AMS. Gates for group 1 forced clockwise cow traffic through the AMS, whereas gates for group 2 forced counterclockwise traffic through the AMS (Figure 1). All gates and alleys were of equal lengths for both groups. The entrance alley (the corridor for the queue

Table 1. Characteristics of cows used to assess access to an automatic milking system

\begin{tabular}{|c|c|c|c|c|}
\hline \multirow[b]{2}{*}{ Item } & \multicolumn{2}{|c|}{ Group 1} & \multicolumn{2}{|c|}{ Group 2} \\
\hline & Mean & SEM & Mean & SEM \\
\hline Parity & 2.61 & 0.25 & 2.4 & 0.21 \\
\hline DIM & 199.91 & 21.09 & 183.65 & 22.3 \\
\hline $\mathrm{BW}(\mathrm{kg})$ & 614.93 & 10.58 & 618.13 & 11.29 \\
\hline Milk yield (kg) & 35.83 & 1.96 & 33.49 & 1.95 \\
\hline Milkings (no.)/cow per day & 3.2 & - & 3.6 & - \\
\hline Presence of horns (\% of group) & 35 & - & 54 & - \\
\hline
\end{tabular}


Feed Alley

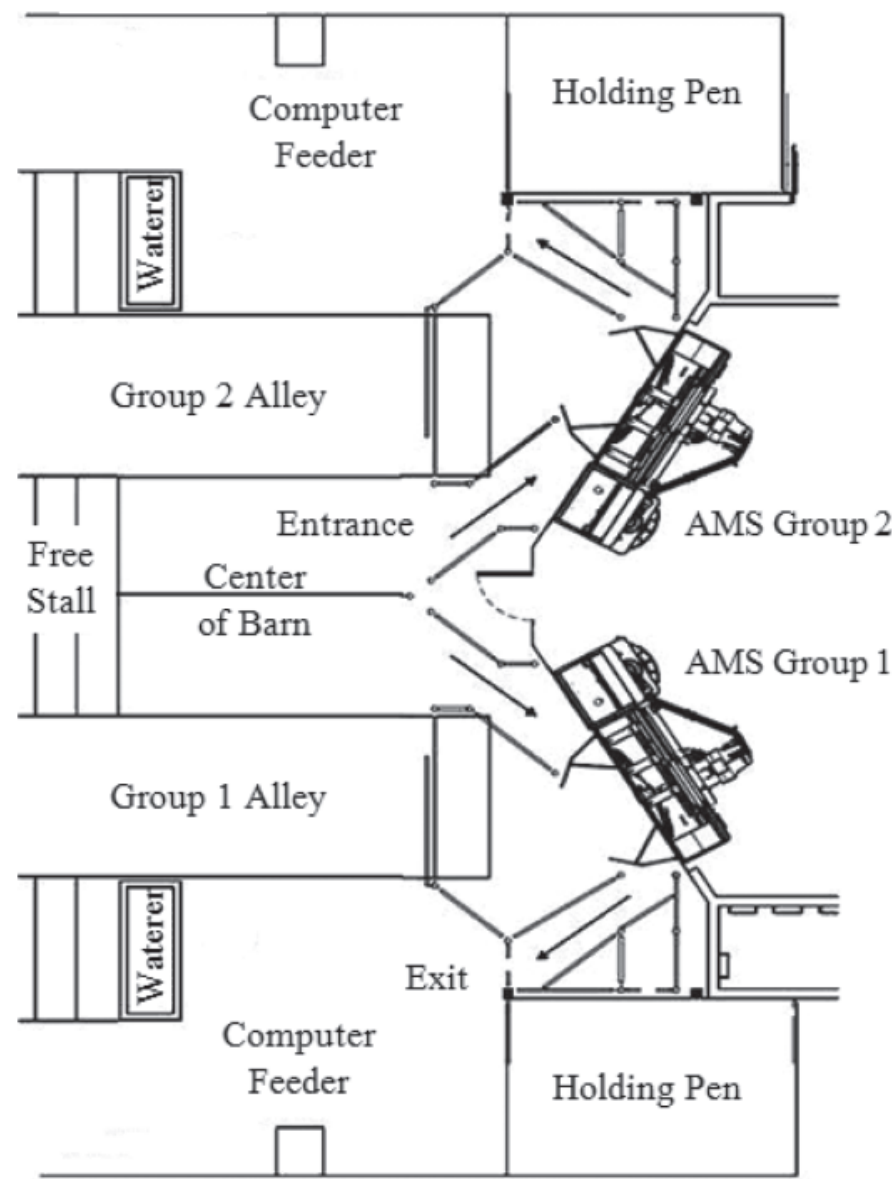

Feed Alley

Figure 1. Cow traffic moved in a counter-clockwise direction through the automatic milking system (AMS) in group 2. Traffic moved in a clockwise direction in group 1.

to milking stall) was $1.8 \times 0.6 \mathrm{~m}$; the exit alley (the corridor leading from milking stall) was $2.4 \times 0.6 \mathrm{~m}$ (Figure 2).

The AMS (Lely Astronaut A3, Lely Industries N.V., Maassluis, the Netherlands), feeding alley, stall layouts, and management practices were identical for both groups. Feeding of a TMR occurred twice daily (0500 and $1500 \mathrm{~h}$ ), and rationing and scheduling were identical for the groups. Cows were offered concentrate pellets during the milking process; the amount of concentrate was dependent upon the individual projected milk yield (Table 2). Footbaths were present in the exit alleys and filled on alternating days with a 5\% copper sulfate solution or water. An electrical movement inductor was present in both AMS and used to encourage cows to step out of the milking stall after $20 \mathrm{~s}$ of hesitation. The shock impulse duration was $10 \mathrm{~s}$, and occurred a maximum of 3 times (after 20, 40, and $60 \mathrm{~s}$
Table 2. Ingredient composition of concentrate pellets fed in the automatic milking system (\% of DM)

\begin{tabular}{lc}
\hline Ingredient & \% of DM \\
\hline Soy hulls & 60.6 \\
Corn fine grind & 13.3 \\
Corn gluten meal & 4.6 \\
Soybean meal & 3.6 \\
SurePro LOL ${ }^{1}$ & 3.6 \\
Molasses cane & 2.2 \\
Tallow & 1.5 \\
\hline
\end{tabular}

${ }^{1}$ SurePro LOL (Land O' Lakes, St. Paul, MN) mix contained $46.5 \%$ CP, $0.8 \%$ fat, $4.5 \%$ ADF, $6.5 \%$ NDF, $0.25 \%$ calcium, $0.67 \%$ phosphorus, $74 \%$ of $\mathrm{CP}$ undegraded intake protein, $26 \%$ of $\mathrm{CP}$ degraded intake protein, $18 \%$ of CP soluble intake protein, $28 \%$ nonfiber carbohydrate, $1.95 \%$ potassium, and $0.3 \%$ magnesium.

of hesitation). The shock intensity increased with each impulse; the intensity began at $2 \mathrm{keV}, 22 \mathrm{MJ}$ and ended at $8.5 \mathrm{keV}, 60 \mathrm{MJ}$.

\section{Experimental Procedure}

Six Sony Super HD cameras (Sony Corporation, Tokyo, Japan) and a 16-channel G-Max 9000 series Digital Video Recorder (Skyway Security, Mauldin, SC) recorded behavior in each group $24 \mathrm{~h} / \mathrm{d}$ for 14 consecu-

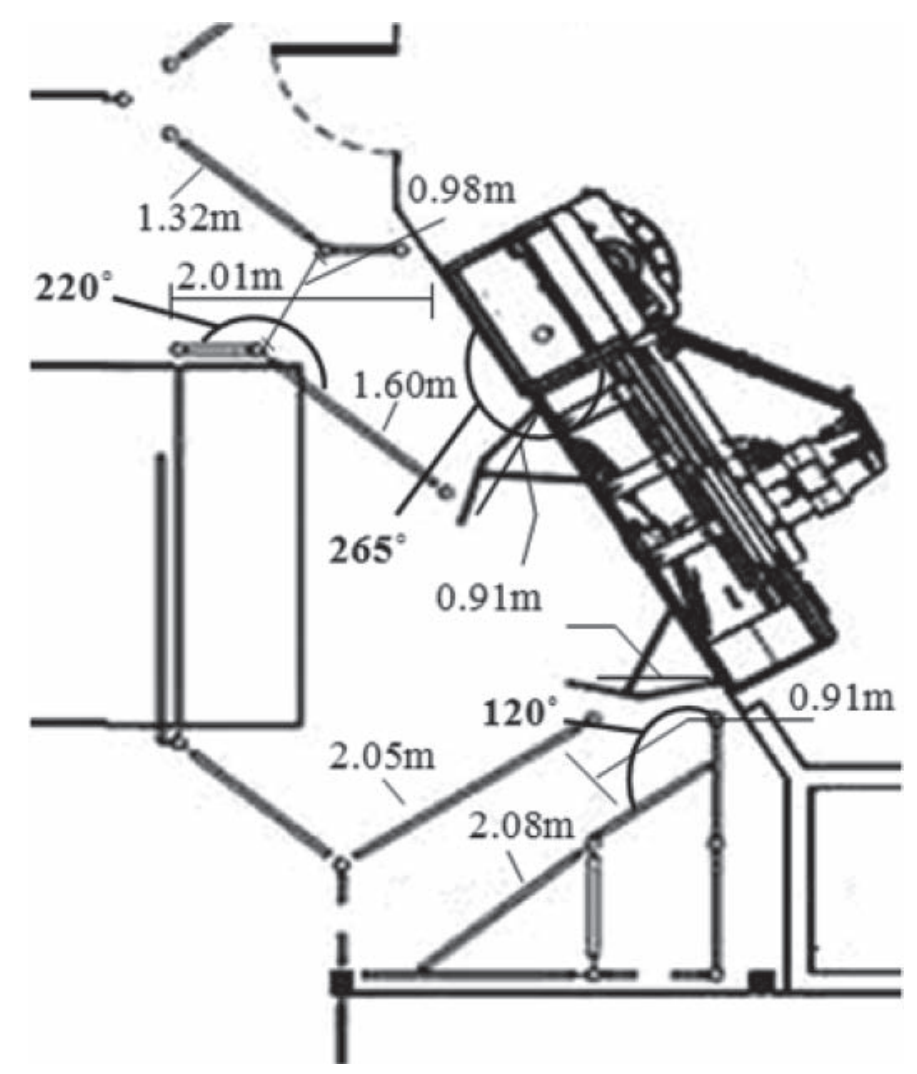

Figure 2. Dimensions for entrance and exit alleys were identical for both groups (group 1 depicted above). 
tive days. Cameras were focused on the holding area in front of the AMS, the AMS itself, and the AMS exit and entrance alleys and gates. Individual cows were identified on video by matching their unique spot patterns to a picture database containing photos of each cow's head, rear, and right and left sides. This method of identification has been used extensively to identify wild animals (Peterson, 1972; Würsig and Jefferson, 1990; Kelly, 2001) and has been validated by comparing accuracy of photo-identification against various forms of electronic identification (Irvine et al., 1982; Scott et al., 1990).

Interobserver Reliability. Three individuals extracted data from the prerecorded video. To assess the reliability of the data being collected between individuals, identical video clips were decoded before the start of the trial and during the middle of data collection by each individual. Identical measurements were recorded and analyzed for similarity between individuals.

AMS Exit Speed. Behavioral observations were recorded for each visit a cow made to the milking stall. The type of visit (unsuccessful or successful) was noted. The time taken for the cow to exit the AMS milking stall (i.e., duration of time from start of AMS exit gate opening to the time of exit gate closing behind focal cow) was recorded. Additionally, circling (i.e., focal cow exited the alley, then made successive attempt(s) to re-enter the AMS) was recorded if applicable.

Hesitation and Blocking Events. Video of cows exiting the AMS was observed to describe the flow of cow traffic in the exit area. Observation began after the exit gate of the milking stall closed behind the focal cow. Cows that ceased walking (i.e., stood still for $>3$ s) in the exit alley were identified as "hesitators," and the duration of hesitation (in seconds) for each event was recorded. This criterion was established based on previous video observations indicating that pauses of $<3 \mathrm{~s}$ between consecutive steps were likely due to factors other than hesitation (e.g., regaining footing). Cows that stood in the holding area at the exit alley 1-way gate and prevented cows in the exit alley from leaving (either passively or actively) were identified as "blockers." Observers recorded the identity and number of cows located in the holding area as the focal cow exited the AMS. Specific locations of the cows in the holding area were noted. Information on individual cow characteristics (stage of lactation, parity, presence and positioning of horns, and milk yield) was used during statistical analysis for evaluation of possible predictors for cows that hesitated or blocked.

Time Budget of the AMS. Durations were recorded for successful milking events (SM: cow enters the AMS and is milked); unsuccessful milking events (UM: cow enters the AMS, but an inefficient amount of time had elapsed since the last milking and she is ejected); robot cleaning events (RC: AMS is unavailable to cow entry due to cleaning); robot empty events (RE: AMS is available for new cow entry, but remains vacant); and back-up events (BU: blocking event escalates until most recently milked cow cannot exit AMS; AMS is unavailable for new cow entry). Durations of each event were summed to create total durations for each event type for each 24 -h period for $14 \mathrm{~d}$. When applicable, the identity of cows involved in each event (SM, UM, and BU) was noted.

\section{Statistics}

All analysis of the data was conducted using SAS v.9.1.3 (SAS Institute Inc., Cary, NC). When appropriate, results were reported as LSM \pm SEM. Results were considered statistically significant at $P<0.05$.

Interobserver Reliability. Analysis of the data was conducted to calculate Spearman coefficients of correlation to determine the reliability of measurements collected by individuals. The accuracy between individuals was determined using the correlation coefficient value for the 2 individuals in question.

AMS Exit Speed. Analysis of the data regarding the time a cow took to exit the milking stall was conducted with the MIXED and GLIMMIX (using the ODDS RATIO option) procedures. Data were log-transformed to fit the assumption of normality. To determine if the type of visit to the AMS (UM or SM) predicted the duration of time to exit the AMS, the following mixed linear model was used (Proc MIXED):

$$
\log _{10}\left(\mathrm{Y}_{\mathrm{ijkl}}\right)=\mu+\mathrm{D}_{\mathrm{i}}+\mathrm{G}_{\mathrm{j}}+\mathrm{V}_{\mathrm{k}}+\mathrm{ID}_{\mathrm{l}}+\mathrm{e}_{\mathrm{ijkl}},
$$

where $\mathrm{Y}=$ duration of time to exit AMS (continuous), $\mu=$ overall mean, $\mathrm{D}=$ random effect of day $(\mathrm{i}=0$ to $13 \mathrm{~d}), \mathrm{G}=$ random effect of group ( $\mathrm{j}=2$ groups $), \mathrm{V}=$ visit type ( $\mathrm{k}=2$ visit types: $\mathrm{UM}$ or $\mathrm{SM}), \mathrm{ID}=$ random effect of individual cow ( $1=1$ to 84 ; total number of cows), and e $=$ residual error.

The probability that UM resulted in a cow circling and re-entering the AMS was investigated using the following model to determine an odds ratio (Proc GLIMMIX):

$$
\begin{gathered}
\log \left(\mathrm{P}_{\text {unsuccessful milking }} / 1-\mathrm{P}_{\text {unsuccessful milking }}\right)= \\
\alpha+\beta \times \mathrm{C}_{\mathrm{i}},
\end{gathered}
$$

where $\alpha=\log$ of odds ratio of unsuccessful visit versus a successful visit under the condition that cow did not circle $\left(C_{i}=0\right)$ or did circle $\left(C_{i}=1\right), \beta=\log$ of odds ratio of unsuccessful visit versus successful visit $-\alpha$, 
and $\mathrm{C}=$ instances of circling ( $\mathrm{i}=2$ types of events; circle, not circle).

Hesitation and Blocking Events. Analysis of the data was conducted using the MIXED procedure for both of the following models. In both instances, data were log-transformed to fit the assumption of normality. The effect of cows present in the general holding area or cows blocking the end of the exit alley on the duration of hesitation was analyzed using the following mixed linear model:

$$
\log _{10}\left(Y_{\mathrm{ijk}}\right)=\mu+\mathrm{D}_{\mathrm{i}}+\mathrm{G}_{\mathrm{j}}+\mathrm{A}_{\mathrm{k}}+\mathrm{e}_{\mathrm{ijk}},
$$

where $\mathrm{Y}=$ duration of hesitation (continuous), $\mu=$ overall mean, $\mathrm{D}=$ random effect of day ( $\mathrm{i}=0$ to $13 \mathrm{~d}$ ), $\mathrm{G}=$ random effect of group $(\mathrm{j}=2$ groups $), A=$ area of cow location ( $\mathrm{k}=3$ locations: holding area, end of exit alley, no cows present), and e $=$ residual error.

The following mixed linear model was used to determine the effect of the number of cows in the holding area on the duration of hesitation:

$$
\log _{10}\left(\mathrm{Y}_{\mathrm{ijkl}}\right)=\mu+\mathrm{D}_{\mathrm{i}}+\mathrm{G}_{\mathrm{j}}+\mathrm{ID}_{\mathrm{k}}+\mathrm{N}_{\mathrm{l}}+\mathrm{e}_{\mathrm{ijk}},
$$

where $\mathrm{Y}=$ duration of hesitation (continuous), $\mu=$ overall mean, $\mathrm{D}=$ random effect of day $(\mathrm{i}=0$ to 13 d), $\mathrm{G}=$ random effect of group $(\mathrm{j}=2$ groups $), \mathrm{ID}=$ random effect of individual cow ( $\mathrm{k}=1$ to 84 ; total number of cows), $\mathrm{N}=$ number of cows in holding area, including the end of the exit alley ( $1=0$ to 5 cows $)$, and $\mathrm{e}=$ residual error.

Hesitating Cow Characteristics. Analysis of the data was conducted using the GLIMMIX procedure (using the ODDS RATIO option). The influence of stage of lactation was investigated with respect to the number of times cows hesitated for long periods $(>500$ s). The random effect of group, BW of the cow, parity, horn positioning, milk yield, and their interactions were removed from the model when determined not significant $(P>0.05)$. The following model was used:

$$
\log \left(\mathrm{P}_{\text {hesitation }} / 1-\mathrm{P}_{\text {hesitation }}\right)=\alpha+\beta \times \mathrm{L}_{\mathrm{i}},
$$

where $\alpha=$ odds ratio of hesitation (>500 s) versus no hesitation, under the condition that cow was in early, mid, or late lactation, $\beta=$ odds ratio of hesitation ( $>500 \mathrm{~s}$ ) versus no hesitation $-\alpha$, and $\mathrm{L}=$ stage of lactation ( $\mathrm{i}=1$ to 3 stages: early, $<100$ DIM, mid, 101-200 DIM, late, >200 DIM).

Blocking Cow Characteristics. Analysis of the data was conducted using the GLIMMIX procedure. The influence of BW, parity, stage of lactation, presence and positioning of horns, and milk yield were investi- gated with cows that frequently blocked ( $\geq 15$ blocking events in a 14-d period; i.e., $>1$ times per day), cows that occasionally blocked ( 7 to 14 blocking events in a 14-d period; i.e., 0.5 to 1 times per day), and cows that almost never blocked ( 0 to 6 blocking events in a 14-d period; i.e., $<0.5$ times per day). Stage of lactation, presence and positioning of horns, milk yield, and their interactions were removed from the model when determined not significant $(P>0.05)$. The following models were used (description of incidences below pertains to 3 following models):

$$
\begin{gathered}
\log \left(\mathrm{P}_{\text {blocking }} / 1-\mathrm{P}_{\text {blocking }}\right)=\alpha+\beta \times \mathrm{P}_{\mathrm{j}} \text { and } \\
\mathrm{W}_{\mathrm{ijk}}=\mu+\mathrm{G}_{\mathrm{i}}+\mathrm{B}_{\mathrm{j}}+\mathrm{e}_{\mathrm{ijk}} .
\end{gathered}
$$

To determine if parity had an effect on BW (i.e., to determine if the variables were correlated), the following model was used with Proc MIXED:

$$
\mathrm{W}_{\mathrm{ijk}}=\mu+\mathrm{G}_{\mathrm{i}}+\mathrm{P}_{\mathrm{j}}+\mathrm{e}_{\mathrm{ijk}},
$$

where $\mu=$ overall mean, $\mathrm{G}=$ random effect of group ( $\mathrm{i}=2$ groups), $\mathrm{P}=$ parity of the cow $(\mathrm{j}=2$ levels: primiparous, multiparous), $\mathrm{W}=$ weight of cow in kilograms, e $=$ residual error.

Upon further investigation of the data set, cows that frequently and occasionally blocked were combined into 1 category to better balance the number of cows in each category ( $\mathrm{n}=50$ never block, $\mathrm{n}=34$ occasionally and frequently block).

AMS Time Budget. Analyses of the data were conducted with the CORR procedure to calculate Pearson coefficients of correlation to determine the relationship between events of interest over a 14-d period. Groups were analyzed separately. Back-up events and UM events were evaluated to determine their relationship with SM events. Additionally, the relationship between $\mathrm{RE}$ and $\mathrm{BU}$ events was investigated. Statistical significance was declared when the correlation coefficient between each pair of the variables was at a probability of $\alpha<0.05$, indicating dependence between the 2 events in focus. The strength of the relationship was determined using the correlation coefficient value for each 2 events in question.

Inter-Day Variability. Analysis of the data was conducted with the MIXED procedure (v.9.1.3, SAS Institute Inc.) to evaluate potential variability between days for each of the 5 events investigated (BU, SM, RE, RC, UM). Statistical differences were based on the LSM of day for SM, UM, and RE when differences were significant at a probability of $\alpha<0.05$. The following mixed linear model was used: 


$$
\mathrm{Y}_{\mathrm{ij}}=\mu+\mathrm{G}_{\mathrm{i}}+\mathrm{D}_{\mathrm{j}}+\mathrm{e}_{\mathrm{ij}},
$$

where $\mathrm{Y}=$ event of interest (BU, SM, RE, RC, UM), $\mu=$ overall mean, $\mathrm{G}=$ random effect of group $(\mathrm{i}=2$ groups), $\mathrm{D}=$ repeated measure of day $(\mathrm{j}=0$ to $13 \mathrm{~d})$, and $\mathrm{e}=$ residual error.

\section{RESULTS}

\section{Interobserver Reliability}

Greater than $85 \%$ reliability was reached between individuals before the start of and midway through data collection.

\section{AMS Exit Speed}

Cows that had a UM experience exited the AMS more slowly $(18.2 \pm 1.33 \mathrm{~s})$ than those who had experienced an SM event $(16.2 \pm 1.09 \mathrm{~s} ; P<0.01)$. In addition, there was a higher probability that cows would circle the milking stall after a UM visit $(0.8 \pm 0.15)$ compared with an SM visit $(0.2 \pm 0.03)$.

\section{Hesitation Events}

Cows hesitated for longer in the exit alley after visiting the AMS if another cow was blocking her exit at the other side of the 1-way exit alley gates $(192.93 \pm 1.11$ s) than if no cows were present in either the holding area or at the 1 -way gates $(88.11 \pm 1.07 \mathrm{~s} ; P<0.001)$. Additionally, cows hesitated longer in the exit alley if cows were located in the general holding area (101.04 $\pm 1.07 \mathrm{~s})$ than if no cows were present $(83.66 \pm 1.08 \mathrm{~s}$; $P<0.001)$. Duration of hesitation in the exit alley was influenced by the number of cows in the holding area $(P<0.001)$. In general, a greater number of cows in the holding area corresponded to greater hesitation times in the exit alley (Figure 3).

Table 3. Distribution of hesitations $>500 \mathrm{~s}$ among cows in different lactation stages

\begin{tabular}{lccc}
\hline & \multicolumn{3}{c}{ Percentage of cows } \\
\cline { 2 - 4 } $\begin{array}{l}\text { Count of } \\
\text { hesitation }>500 \mathrm{~s}\end{array}$ & Early & Mid & Late \\
\hline 0 & 26 & 17 & 19 \\
1 & 4 & 7 & 12 \\
2 & 1 & 2 & 9 \\
3 & 0 & 1 & 2 \\
\hline
\end{tabular}

${ }^{1}$ Early lactation cows are defined as being 1-100 DIM; mid lactation cows are defined as being 101-200 DIM; late lactation cows are defined as being $\geq 201$ DIM.

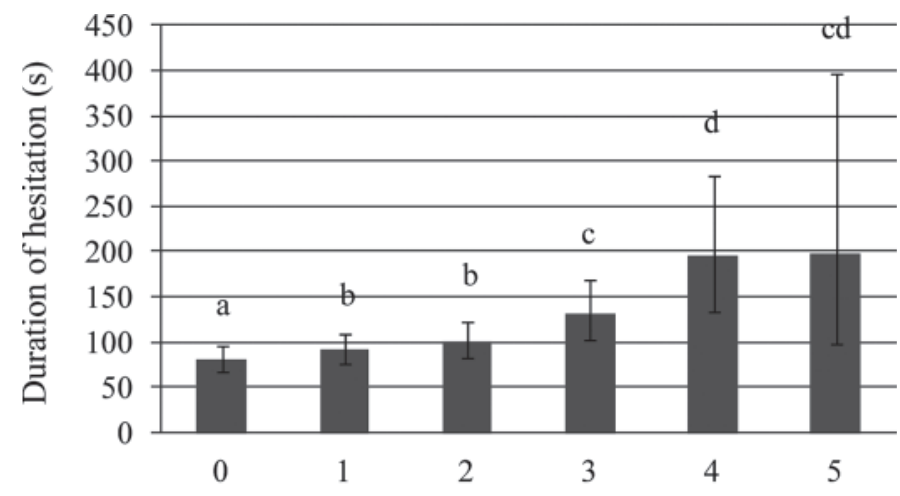

Number of cows located in the holding area

Figure 3. Mean duration of hesitation for cows leaving the exit alley with 0 to 5 cows located in holding area. Original analysis was performed on transformed data; graph represents back-transformed data and includes confidence intervals of the back-transformed data. The duration of hesitation increased significantly as the number of cows in the holding area increased. Means followed by the same letter are not different from each other $(P<0.05)$.

\section{Hesitating Cow Characteristics}

Late $(0.55 \pm 0.096)$ and mid $(0.36 \pm 0.1)$ lactation cows had a greater probability than early lactation cows $(0.15 \pm 0.07)$ of hesitating in the exit alley for periods $>500 \mathrm{~s}$ (Table 3 ). The average successful milking event occurred for $449 \mathrm{~s}$; therefore, $500 \mathrm{~s}$ was chosen to represent a potentially debilitating hesitation period. If a cow was still standing in the exit alley when a recently milked cow tried to leave the milking stall, greater potential existed for a BU event, in which the AMS cannot accept the next cow for milking.

\section{Blocking Cow Characteristics}

Parity influenced frequency of cows blocking other cows from leaving the AMS exit alley $(P<0.05)$. Primiparous cows more frequently blocked $(0.60 \pm 0.13)$ compared with multiparous cows $(0.29 \pm 0.09 ; P<$ $0.05)$. In addition, BW was related to blocking grade $(P$ $<0.05)$, with lighter-weight cows $(547.06 \pm 14.59 \mathrm{~kg})$ having a higher blocking grade compared with heavier cows $(657.53 \pm 15.05 \mathrm{~kg})$. As expected, multiparous cows were heavier $(641.40 \pm 8.22 \mathrm{~kg})$ than primiparous cows $(562.08 \pm 11.52 \mathrm{~kg} ; P<0.001)$; a relationship was found between age and $\mathrm{BW}(\mathrm{r}=0.46 ; P<0.01)$.

\section{Time Budget of the AMS}

We observed no relationship between UM and SM events for either group 1 or group 2 and no relationship between SM and BU events in group 1; however, we observed a trend toward a negative relationship for these 


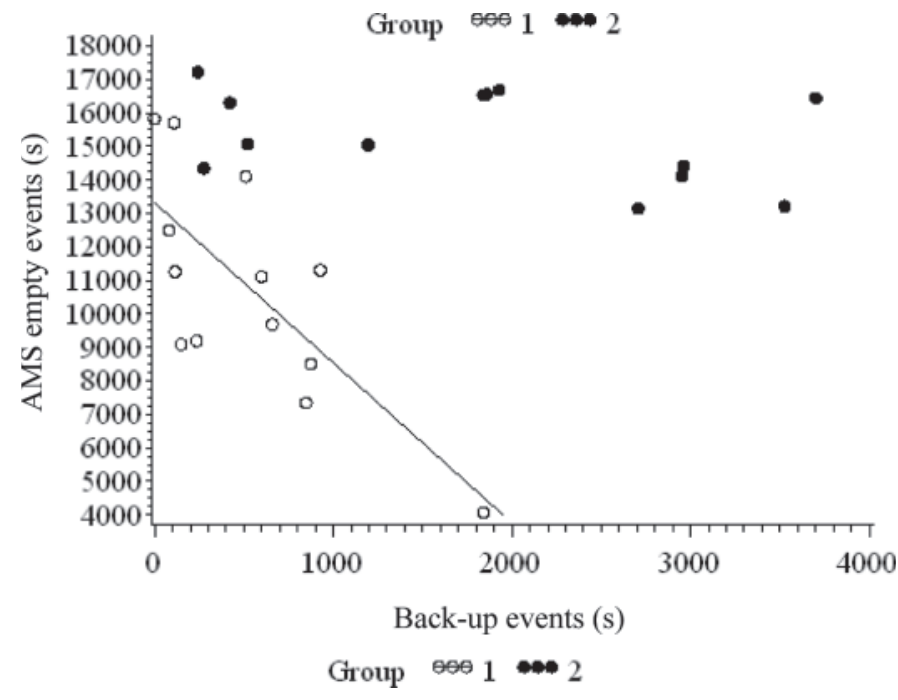

Figure 4. A negative relationship between automatic milking system (AMS) empty and back-up events was observed in group $1(\mathrm{r}=$ $-0.74, P<0.01)$. No relationship existed between the 2 events in group $2(\mathrm{r}=-0.14, P=0.61)$.

2 events in group $2(\mathrm{r}=-0.49, P=0.07)$. A negative relationship was observed between $\mathrm{RE}$ and $\mathrm{BU}$ events in group $1(\mathrm{r}=-0.74, P<0.01$; Figure 4$)$; however, no such relationship between the 2 events was determined in group $2(\mathrm{r}=-0.14, P=0.61$; Figure 4$)$.

\section{Inter-Day Variability}

The duration of SM, RE, and UM events varied significantly by day over the $14 \mathrm{~d}$ examined $(P<0.05)$, whereas the duration of $\mathrm{BU}$ events $(P=0.24)$ and $\mathrm{RC}$ events $(P=0.93)$ remained consistent across the days. Figure 5 depicts the percentages of time the events of interest occurred over a 24 -h period ( $14 \mathrm{~d}$ total).

\section{DISCUSSION}

Automatic milking systems have the potential to increase milk production compared with parlor systems that milk cows twice daily (de Koning et al., 2002; Rotz et al., 2003; Wade et al., 2004). The number of milking events achieved per cow daily in an AMS can vary and depends upon individually set milking intervals for each cow, a cow's motivation to access the milking stall, cow traffic through the barn, and the frequency with which farm staff fetches overdue cows. It is important that the AMS operate in an efficient manner so that each cow can achieve at least her designated number of milking events each day and, in turn, produce the maximum amount of milk possible. Additionally, when considering cow behavioral needs and welfare, factors that result in cows standing in or near the AMS longer could reduce time spent at the feed bunk or lying in stalls (Uetake et al., 1997). Thus, any factors resulting in a potential decrease of AMS availability should be examined.

Unsuccessful milking events had previously been related to cows exiting the milking stall more slowly compared with cows that had experienced a successful milking event (Stefanowska et al., 1999). Our study supported those earlier results. One of the key factors motivating cows to access the milking stall is the offer of concentrate upon entry (Prescott et al., 1998). It is probable that cows entering the milking stall expected

\section{Group 1}

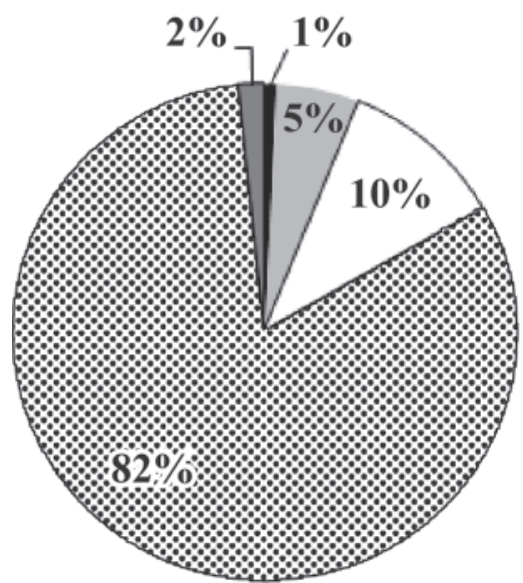

\section{Group 2}

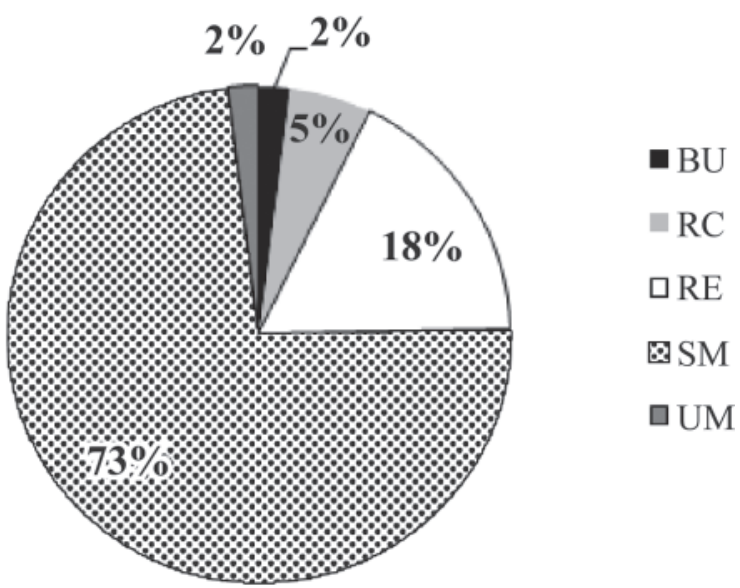

Figure 5. Average percentage of time for each event: back-up (BU; 1\%), robot cleaning (RC; 5\%), robot empty (RE; 14\%), successful milking (SM; 78\%), and unsuccessful milking (UM; $2 \%$ ) events across both groups over a 24 -h period. 
to receive a concentrate reward regardless of whether or not they were milked. The additional time taken to exit the milking stall by UM cows may have been a reflection of an expectation to receive feed upon arrival, and reluctance to leave when the predicted event did not occur. Furthermore, cows that had experienced a UM event were more likely to circle and return immediately to the AMS compared with cows that experienced an SM event. Under these circumstances, UM events may be described as being inefficient; additional time spent exiting the milking stall coupled with successive circling events waste AMS time and may deter or delay cows that are waiting and ready to be milked (Stefanowska et al., 1999).

The presence of cows in the holding area and in the area behind the 1-way exit alley gates encouraged longer bouts of hesitation in the exit alley by cows leaving the AMS. These results support Stefanowska et al. (1999). Specifically in this experiment, a positive relationship existed between the number of cows located in the holding area and the duration of hesitation by a cow in the exit alley. This suggests that a balance must be achieved in the holding area. Certainly, the objective of the holding area is to encourage new cow approach for milking events by providing a large area for a cow queue. Cows lingering unnecessarily in the holding area, particularly if they are affecting the behavior of cows attempting to access or exit the system, could reduce efficiency of the AMS (Stefanowska et al., 1999).

Hesitation events occurred frequently even when no cows were present in the holding area or directly in front of the exit alley gates. Cows in late and mid lactation were more likely to hesitate in the exit alley for longer periods compared with those in early lactation. Late lactation cows were most likely to hesitate for periods longer than $8 \mathrm{~min}$ in the exit alley. Early lactation cows adopted a more efficient feeding strategy to support a higher milk yield, and thus, may have been more eager to enter the feeding alley after milking (Cooper et al., 2010). Winter and Hillerton (1995) reported that the slowest (and oldest) cow in their experimental group took 7.03 min to exit the area around the AMS; however, their observational group included early lactation cows only. Age or parity did not affect the duration of hesitation in our experiment.

Parity was a predictor of cows that blocked the exit alley. Furthermore, an interaction between parity and BW was determined; specifically, lighter-weight primiparous cows were more likely blockers than heavier primiparous cows. Lighter primiparous cows were thought to be subordinate to their heavier, multiparous herdmates (Bouissou, 1972; Phillips and Rind, 2001) and thus, would not be expected to be successful blockers, because forcing another cow to stop walking would seem to require a social advantage on the part of the blocker. The design of the gates around the AMS may have provided these lower-ranking cows with physical barriers that allowed them to block. It has been suggested that animals value resources differently, and dominance relationships change depending on the resource (Val-Laillet et al., 2008). Thus, it is possible that the lighter-weight primiparous cows (assumed lower ranking) block others as a means to improve their status and their subsequent access to the milking stall. Alternatively, a study suggests that the degree of aggressiveness (measured by the number of active aggressive interactions initiated by an individual), rather than the BW or parity of the cow, was more often a predictor of dominance (Collis, 1976). As the degree of aggressiveness was not determined for cows in this study, it may be another predictor for blocking that was not considered.

Unsuccessful milking events did not share relationships with SM events. Therefore, time wasted by circling cows did not affect availability of the AMS to SM; however, hidden costs may be associated with this behavior. The AMS in group 2 was empty $18 \%$ of the day; thus, it was possible that time spent in BU events by cows in group 2 could have been absorbed by available RE time.

The time budget difference between groups was unexpected and subsequently difficult to interpret. Neither AMS milking unit was used to capacity, with an experimental group size of 42 cows per AMS instead of the frequently recommended 60 cows per AMS, which may have allowed for greater flexibility in time budgets. It will be important for future research to determine if $\mathrm{BU}$ events generally share a relationship with the amount of time spent SM or with RE time, particularly in AMS that are used to capacity. Perhaps even when at capacity, different social dynamics within groups of cows or variable behavior of individuals will prove to have the largest influence on AMS time budgets. The AMS has been developed in part to give the cows more control and flexibility in their environment, and a less predictable operation may be the result.

\section{CONCLUSIONS}

Several factors may affect the availability of an AMS. Primiparous cows blocked others from leaving the exit alley more frequently than did multiparous cows. Unsuccessful milking events resulted in a longer AMS exit time for the cow, but did not affect the amount of time spent successfully milking each day. The effect of the time the AMS spent in a back-up event on the time the AMS spent successfully milking varied between the groups, suggesting that cow behavior and group 
dynamics may influence the availability, efficiency, and overall success of an AMS. It should be noted that this research includes only one experimental herd and barn design, and thus, provides a very specific description of events. In the future, an inclusion of numerous experimental herds, facility designs, and differing group sizes may help lead the industry to an ideal gate and alley configuration to promote optimum availability of the AMS for successful milking events.

\section{ACKNOWLEDGMENTS}

Funding support for this research was generously provided by Michigan State University AgBioResearch to Janice Siegford. Additional support was received from a grant to Michigan State University from the W. K. Kellogg Foundation (Battle Creek, MI) to establish a pasture-based dairy program at the Kellogg Biological Station (KBS, Hickory Corners, MI). We thank Rob Ashley (Michigan State University, Hickory Corners) and the KBS dairy barn staff for their assistance with this project. We gratefully acknowledge the statistical expertise of Wei Wang (Statistical Consulting Center, Michigan State University, East Lansing) for his assistance in the planning and analysis of this project. We also thank Courtney Daigle, May Dik, Krista Beeker, Kelly Jaynes, and Melissa Elischer (all of the Animal Behavior and Welfare Group, Michigan State University, East Lansing) for their help decoding video and organizing data. Special thanks to Dave Beede (Michigan State University, East Lansing), Karen Plaut and Michael Schutz (both of Purdue University, West Lafayette, IN), and Trevor DeVries (University of Guelph, Guelph, ON, Canada) for their comments and suggestions concerning the manuscript.

\section{REFERENCES}

Bouissou, M. F. 1972. Influence of body weight and presence of horns on social rank in domestic cattle. Anim. Behav. 20:474-477. http://dx.doi.org/10.1016/S0003-3472(72)80011-3.

Collis, K. A. 1976. An investigation of factors related to the dominance order of a herd of dairy cows of similar age and breed. Appl. Anim. Ethol. 2:167-173. http://dx.doi.org/10.1016/03043762(76)90044-4.

Cooper, M. D., D. R. Arney, and C. J. Christie-Phillips. 2010. The motivation of high- and low-yielding dairy cows to obtain supplementary concentrate feed. J. Vet. Behav. Clin. Appl. Res. 5:75-81. http://dx.doi.org/10.1016/j.jveb.2009.09.045.

de Koning, K., Y. van der Vorst, and A. Meijering. 2002. Automatic milking experience and development in Europe. Pages I-1 to I-11 in The First North Am. Conf. Robotic Milking. Wageningen Academic Press, Wageningen, the Netherlands.

Hermans, G. G. N., A. H. Ipema, J. Stefanowska, and J. H. M. Metz. 2003. The effect of two traffic situations on the behavior and performance of cows in an automatic milking system. J. Dairy Sci. 86:1997-2004. http://dx.doi.org/10.3168/jds.S00220302(03)73788-6.

Irvine, A. B., R. S. Wells, and M. D. Scott. 1982. An evaluation of techniques for tagging small odontocete cetaceans. Fish Bull. 80:135-143.

Kelly, M. J. 2001. Computer-aided photograph matching in studies using individual identification: An example from Serengeti cheetahs. J. Mammal. 82:440-449.

Melin, M., G. G. N. Hermans, G. Pettersson, and H. Wiktorsson. 2006. Cow traffic in relation to social rank and motivation of cows in an automatic milking system with control gates and an open waiting area. Appl. Anim. Behav. Sci. 96:201-214. http://dx.doi. org/10.1016/j.applanim.2005.06.013.

Peterson, J. C. 1972. An identification system for zebra. East Afr. Wildl. J. 10:59-63.

Phillips, C. J. C., and M. I. Rind. 2001. The effects on production and behavior of mixing uniparous and multiparous cows. J. Dairy Sci. 84:2424-2429. http://dx.doi.org/10.3168/jds.S00220302(01)74692-9.

Prescott, N. B., T. T. Mottram, and A. J. F. Webster. 1998. Relative motivations of dairy cows to be milked or fed in a Y-maze and an automatic milking system. Appl. Anim. Behav. Sci. 57:23-33. http://dx.doi.org/10.1016/S0168-1591(97)00112-3.

Rodenburg, J. 2007. Field observations on barn layout and design for robotic milking of dairy cows. Sixth Int. Dairy Housing Conf., Minneapolis, MN. ASABE Publication Number 701P0507e. ASABE, St. Joseph, MI.

Rotz, C. A., C. U. Coiner, and K. J. Soder. 2003. Automatic milking systems, farm size, and milk production. J. Dairy Sci. 86:41674177. http://dx.doi.org/10.3168/jds.S0022-0302(03)74032-6.

Scott, M. D., R. S. Wells, A. B. Irvine, and B. R. Mate. 1990. Tagging and marking studies on small cetaceans. Pages 489-514 in The Bottlenose Dolphin. S. Leatherwood and R. R. Reeves, ed. Academic Press, San Diego, CA.

Stefanowska, J., N. S. Tiliopoulos, A. H. Ipema, and M. M. W. B. Hendriks. 1999. Dairy cow interactions with an automatic milking system starting with 'walk-through' selection. Appl. Anim. Behav. Sci. 63:177-193. http://dx.doi.org/10.1016/S0168-1591(99)00012$\mathrm{X}$.

Uetake, K.. J. F. Hurnik, and L. Johnson. 1997. Behavioral pattern of dairy cows milked in a two-stall automatic milking system with a holding area. J. Anim. Sci. 75:954-958.

Val-Laillet, D., D. M. Veira, and M. A G. von Keyserlingk. 2008. Short communication: Dominance in free-stall-housed dairy cattle is dependent upon resource. J. Dairy Sci. 91:3922-3926. http:// dx.doi.org/10.3168/jds.2008-1332.

Wade, K. M., M. A. P. M. van Asseldonk, P. B. M. Berentsen, W Ouweltjes, and H. Hogeveen. 2004. Economic efficiency of automatic milking systems with specific emphasis on increases in milk production. Pages 62-67 in Automatic Milking-A Better Understanding. A. Meijering, H. Hogeveen, and C. J. A. M. de Koning, ed. Wageningen Academic Publishers, Wageningen, the Netherlands.

Winter, A., and J. E. Hillerton. 1995. Behavior associated with feeding and milking of early lactation cows housed in an experimental automatic milking system. Appl. Anim. Behav. Sci. 46:1-15. http:// dx.doi.org/10.1016/0168-1591(95)00628-1.

Würsig, B., and T. A. Jefferson. 1990. Methods of photo-identification for small cetaceans. Rep. Int. Whaling Comm. 12:43-52. 